\title{
Ethics and injury risk in World Rugby and England Rugby tackle-height trial
}

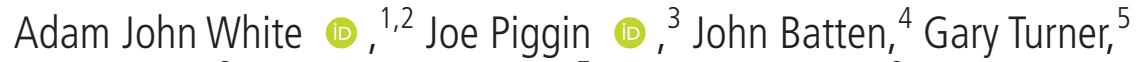 \\ Alan Pearce, ${ }^{6}$ Rachael Bullingham, ${ }^{7}$ Eric Anderson ${ }^{8}{ }^{8}$
}

\section{CONCUSSION IN RUGBY}

Concerns about concussion in contact sport have permeated debate within sports medicine. ${ }^{1-4}$ Considerable scientific attention has been focussed on the short-term and long-term outcomes of concussions, as well as the strategies to reduce the risk of traumatic brain injury. The practicalities and impact of altering rules (laws) in sport-including the evaluation of outcomes-are often considered.

In the elite setting, World Rugby recently opted to lower the permitted tackle height in Championship Rugby. ${ }^{56}$ We believe this research intervention ${ }^{7}$ raises some ethical questions around informed consent and the right to withdraw, since the players were contractually compelled to participate. Unfortunately, rather than reducing injury risk, this research intervention also resulted in an increased risk of concussion.

Thus, we alert the reader to issues relating to the ethics and increased risk of injury following this research intervention and make some recommendations for the future.

\section{ETHICAL PRACTICES}

We are concerned by the ethical approval and participant selection processes employed in this research intervention. Indeed, this trial was conducted by World Rugby following research published by World Rugby employees. ${ }^{5} 6$ World Rugby then subsequently imposed this trial on Championship Rugby players in the UK to test the hypothesis that lowering tackle height would lower concussion incidence.

\section{${ }^{1}$ Oxford Brookes University Faculty of Health and Life Sciences, Oxford, UK \\ ${ }^{2}$ Newcastle University, Newcastle upon Tyne, UK ${ }^{3}$ School of Sport, Exercise and Health Sciences, Loughborough University, Loughborough, UK ${ }^{4}$ Department of Sport and Exercise, The University of Winchester, Winchester, UK \\ 5 University of Winchester, Winchester, UK \\ ${ }^{6}$ Department of Rehabilitation, Nutrition and Sport, La Trobe University - Melbourne Campus, Melbourne, Victoria, Australia \\ ${ }^{7}$ University of Gloucestershire, Cheltenham, UK ${ }^{8}$ Department of Sport and Exercise, University of Winchester, Winchester, UK}

Correspondence to Dr Adam John White, Oxford Brookes University Faculty of Health and Life Sciences, Oxford OX3 OFL, UK; adamwhitephd@gmail.com
Given that players are employed by their clubs to play rugby, it is extremely unlikely they had the ability to consent to participate or the right to withdraw from the trial without penalty or prejudice. ${ }^{8}$ This is particularly concerning given that 'the majority of players felt that reducing tackle height would result in more, rather than less, concussions'.

\section{TRIAL FINDINGS}

Another area of concern for us relates to the injury risk that followed this research intervention. Specifically, this trial reduced the permitted height of the tackle from the line of the shoulder to the line of the armpit in elite men's rugby. Although not statistically significant, the result of the trial was that there were 16.9 concussions per 1000 playing-hours in the non-intervention period compared with 22.2 concussions per 1000 playing-hours during the intervention. This equates to a 30\% greater relative risk of concussion.

The impact of this trial was greatest on the tackler, whereby '...concussion incidence rates for tacklers were 6.9 per 1000 hours in the control and 13.2 per 1000 hours in the intervention period'. Therefore, the trial increased the risk of injury in the form of mild traumatic brain injuries to the participants within Championship Rugby.

Although some may consider the decision to run this intervention separate from the research-making it not under the purview of research ethics-the research in question was the law change. Indeed, the authors have reported this research as an 'intervention' study. ${ }^{7}$ Thus, it becomes difficult to accept any assertion that tries to separate the trial from the research, a common strategy used to erode the nature of participant informed consent in trials. ${ }^{9}$

The ethical approval cited by the researchers refers to observational injury surveillance and does not acknowledge any intervention (ie, the change to the laws of the game)

We also identify the potential entanglement of researcher and corporate interests; whereby the researchers are employed and funded directly by the sport. The decision from the Rugby Football Union and
World Rugby to (rightly) stop the trial shows how intertwined the research was within the governance of the trial. Thus, further consideration should be given to the governance process and oversight of approving rule (law) changes that may increase the risk of injury to participants.

Some may argue that World Rugby and England Rugby have a responsibility to fund and/or undertake research into player safety. We have no intention of stifling any such endeavour. However, the potential entanglement of researcher and corporate interests require careful consideration, alongside ethics and sport governance. The authors of this research did declare their conflicts of interest.

\section{RECOMMENDATIONS}

World Rugby should be supported in attempting to decrease concussions within the sport. ${ }^{1}$ Notwithstanding, it is concerning that this trial was conducted without what we consider to be sufficient in regard to the informed choice of human participants, as well as the right to withdraw without prejudice or penalty. ${ }^{8}$

This is particularly concerning given that 'most of the players' predicted an increase in concussion was likely. Players were then subsequently placed at an increased risk of injury-a risk that is already higher than other team sports. ${ }^{10}$ Thus, given the ethical concerns identified and the increased risk of injury, research should not repeat these mistakes.

We recommended that World Rugby and England Rugby have all research and interventions externally scrutinised by scientists from outside the rugby community or higher education institutions funded by them. This will encourage critical dialogue and mitigate the likelihood of unethical research practices.

In addition, informed consent and the right to withdraw without penalty or prejudice should be central components to any future intervention-based researchwhich suggests that imposing changes on the professional game before substantiated research evidence and dialogue (eg, with the Rugby Players Association) should be avoided.

Twitter Adam John White @adamjohnwhite, John Batten@JBatz85 and Eric Anderson @WinchesterProf

Contributors All authors were involved in the development and authorship of this editorial.

Funding The authors have not declared a specific grant for this research from any funding agency in the public, commercial or not-for-profit sectors.

Patient consent for publication Not required.

Provenance and peer review Not commissioned; externally peer reviewed. 


\section{Editorial}

(c) Author(s) (or their employer(s)) 2020. No commercial re-use. See rights and permissions. Published by BMJ.

\section{D) Check for updates}

To cite White AJ, Piggin J, Batten J, et al. $\mathrm{Br} J$ Sports Med Epub ahead of print: [please include Day Month Year]. doi:10.1136/bjsports-2020-101983 Accepted 3 July 2020

\section{CLinked}

http://dx.doi.org/10.1136/bjsports-2019-101557

Br J Sports Med 2020;0:1-2

doi:10.1136/bjsports-2020-101983

ORCID iDs

Adam John White http://orcid.org/0000-0002-68658197

Joe Piggin http://orcid.org/0000-0002-1361-6248
Eric Anderson http://orcid.org/0000-0002-2601-4385

\section{REFERENCES}

1 Batten J, White AJ, Anderson E, et al. From management to prevention: the new cure for sports concussion. Br J Sports Med 2016:50:1293-4.

2 Pollock AM, White AJ, Kirkwood G. Evidence in support of the call to ban the tackle and harmful contact in school rugby: a response to world rugby. $\mathrm{Br} J$ Sports Med 2017;51:1113-7.

3 White AJ, Batten J, Kirkwood G, et al. 'Pre-activity movement control exercise programme to prevent injuries in youth rugby': some concerns. Br I Sports Med 2019;53:525-6.

4 Cross MJ, Tucker R, Raftery M, et al. Tackling concussion in professional rugby Union: a casecontrol study of tackle-based risk factors and recommendations for primary prevention. Br I Sports Med 2019;53:1021-5.

5 Tucker R, Raftery M, Kemp S, et al. Risk factors for head injury events in professional rugby Union: a video analysis of 464 head injury events to inform proposed injury prevention strategies. Br I Sports Med 2017:51:1152-7.

6 Tucker R, Raftery M, Fuller GW, et al. A video analysis of head injuries satisfying the criteria for a head injury assessment in professional rugby Union: a prospective cohort study. Br J Sports Med 2017;51:1147-51.

7 Stokes KA, Locke D, Roberts S, et al. Does reducing the height of the tackle through law change in elite men's rugby Union (the Championship, England) reduce the incidence of concussion? A controlled study in 126 games. Br J Sports Med 2019. doi:10.1136/ bjsports-2019-101557. [Epub ahead of print: 19 Dec 2019].

8 Harriss DJ, Atkinson G. Update-Ethical standards in sport and exercise science research. Int I Sports Med 2011;32:819-21.

9 Shepherd L, Macklin R. Erosion of informed consent in U.S. research. Bioethics 2019;33:4-12.

10 Roberts SP, Trewartha G, England M, et al. Epidemiology of time-loss injuries in English community-level rugby Union. BMJ Open 2013:3:e003998. 